\title{
A scientific note on reversion of fluvalinate resistance to a degree of susceptibility in Varroa destructor
}

\author{
Patti ELZEN ${ }^{\text {a† }}$, David WESTERVELT ${ }^{\mathrm{b}}$ \\ a USDA-ARS, 2413 E. Hwy. 83, Weslaco, TX 78596, USA \\ b Florida Dept. Agric., Division of Plant Industry, 1911 SW 34th St., Gainesville, FL 32614, USA
}

(Received 11 February 2003; revised 26 November 2003; accepted 13 December 2003)

Varroa destructor / fluvalinate / resistance

Varroa destructor is the most serious parasitic pest attacking honey bees in the U.S., causing death of colonies if left uncontrolled. The predominant compound used in the U.S. to control V. destructor has been fluvalinate. Since 1998, however, resistance by $V$. destructor to this compound has been documented for diverse regions of the U.S. (Elzen et al., 1999)

With other agricultural pests that have developed resistance, cessation of compound use can result in some degree of susceptibility (Georghiou and Taylor, 1986). Such a question has been raised for $V$. destructor fluvalinate resistance in the US.

We established two groups of highly resistant $V$. destructor in bee colonies in Umatilla, Florida, in June 1998. Sixteen colonies were established in previously unused hive equipment and foundation. Frames of brood collected from $V$. destructorinfested colonies that experienced fluvalinate failure were added to the 16 colonies. Colonies, each consisting of a brood box and one super, were positioned in two widely separated groups (8 colonies per group) 3 miles from other colonies. One group was designated selected with fluvalinate, the other designated as unselected.

The method of Elzen et al. (1999) was used to assess resistance levels in the two groups. Mites were collected from brood cells and removed using a camel hair brush. Mites were placed in $20 \mathrm{~mL}$ glass vials that contained a residual film of technical grade fluvalinate, in a dosage previously found to cause $80-90 \%$ mortality of susceptible mites after 24 hours of exposure $-2.4 \mu \mathrm{g}$ per vial (Elzen et al., 1999). Significantly lower mortality observed at this dose was considered confirmation of resistance in the tested population. Control vials contained no fluvalinate. Three mites were place in each vial and vials were replicated 15 times at each sample date for each colony within both groups tested. Two to four colonies in each group were tested at each date and results were pooled for each group to obtain mean percent mortality. Resulting mean percent mortality between initial and final dates for each group, after confirmation of homogeneity within pooled groups, were compared by chi-square analysis (Zar, 1974). Fluvalinate selection pressure was maintained in the treated group by application of Apistan ${ }^{\circledR}$ strips (10\% fluvalinate) in group colonies; fresh strips were inserted for 24 hours on 9 Sep 98 and 5 Feb 99. Assays were initiated 4 Aug 98; tests were terminated 3 May 99 due to increasing mortality of colonies caused by high $V$. destructor numbers.

Table I shows the results of testing of selected and unselected $\mathrm{V}$. destructor groups over a ninemonth period. The unselected population showed significant increased susceptibility over time, with a final level of ca. $50 \%$ mortality compared to ca. $10 \%$ initial mortality level $(P<0.05)$. Initial and final mortality levels for the selected group of colonies remained statistically equivalent $(P>0.05)$.

The increase of susceptibility of the unselected group was significant, but modest. Such reversion in resistance to fluvalinate is also consistent with results found by Milani and Della Vedova (2002) in Italy. They attribute the slow reversion they observed as characteristic of monooxygenases. In the population we tested, samples of mites from selected colonies were determined to exhibit resistance moderated by target site insensitivity (Wang et al., 2002)

It is possible that the increase of susceptibility found in our study may have been due to influx of susceptible mites from locally managed colonies. While possible, this is unlikely, as both were maintained 3 miles from another apiary and most apiaries in the locality were experiencing fluvalinate resistance. Incursion of susceptible mites from feral bee nests was also unlikely, due to probable

\footnotetext{
$\dagger^{\text {Deceased. }}$
} 
Table I. Susceptibility of $V$. destructor to fluvalinate after selection pressure and no selection pressure.

\begin{tabular}{lccccc}
\hline & & \multicolumn{3}{c}{ Mean Percent Mortality ( \pm SD) } \\
Colony Type & 4 Aug 98 & 10 Sep 98 & 27 Oct 98 & 4 Feb 99 & 3 May 99 \\
\hline Unselected & $8.9(2.9)$ & $23.6(4.2)$ & $25.5(4.4)$ & $41.7(6.6)$ & $48.4(6.7)^{*}$ \\
Selected & $12.8(3.4)$ & $29.4(4.6)$ & $18.9(3.7)$ & $25.0(6.1)$ & $17.8(5.1)$ \\
\hline
\end{tabular}

Value followed by an asterisk indicate significant difference between initial and final mortality within a row (chi-square, $P<0.05$ ). Standard deviations calculated based on a binomial distribution.

elimination of feral honey bee populations by $V$. destructor (Hoopingarner and Waller, 1992).

\section{Note scientifique sur la réversion de la résistance de Varroa destructor au fluvalinate à un degré de sensibilité.}

Eine wissenschaftliche Notiz über die Umkehrung der Fluvalinatresistenz von Varroa destructor bis zu einem Grad von Empfindlichkeit.

\section{REFERENCES}

Elzen P.J., Eischen F.A., Baxter J.R., Elzen G.W., Wilson W.T. (1999) Detection of resistance in US Varroa jacobsoni Oud. (Mesostigmata: Varroidae) to the acaricide fluvalinate, Apidologie 30, 13-17.
Georghiou G.P., Taylor C.E. (1986) Factors influencing the evolution of resistance, in: Pesticide Resistance: Strategies and Tactics for Management, Washington D.C., National Academy Press, pp. 157-169.

Hoopingarner R.A., Waller G.D. (1992) Crop Pollination, in: Graham J.M. (Ed.), The hive and the honey bee, Dadant and Sons, Hamilton, Illinois, pp. 1043-1082.

Milani N., Della Vedova G. (2002) Decline in the proportion of mites resistant to fluvalinate in a population of Varroa destructor not treated with pyrethroids, Apidologie 33, 417-422.

Wang R., Liu Z., Dong K., Elzen P.J., Pettis J., Huang Z.Y. (2002) Association of novel mutations in a sodium channel gene with fluvalinate resistance in the mite, Varroa destructor, J. Apic. Res. 40, $17-25$.

Zar J.H. (1974) Biostatistical Analysis, Prentice-Hall Inc., Englewood Cliffs, New Jersey. 